Ann. Geophysicae 16, 853-865 (1998) @ C EGS - Springer-Verlag 1998

\title{
Parametrization of the precipitation in the Northern Hemisphere and its verification in Mexico
}

\author{
V. M. Mendoza, B. Oda, J. Adem \\ Centro de Ciencias de la Atmósfera, Universidad Nacional Autónoma de México, 04510, México D. F., México
}

Received: 5 February 1997 / Revised: 15 December 1997 / Accepted: 17 December 1997

\begin{abstract}
To improve results in monthly rainfall prediction, a parametrization of precipitation has been developed. The thermodynamic energy equation used in the Adem thermodynamic model (ATM) and the Clausius and Clapeyron equation, were used to obtain a linear parametrization of the precipitation anomalies as a function of the surface temperature and the $700 \mathrm{mb}$ temperature anomalies. The observed rainfall in Mexico over 36 months, from January 1981 to December 1983, was compared with the results obtained of the heat released by condensation, which is proportional to precipitation, using our theoretical formula, and those obtained using a statistical formula, which was derived for the ATM using 12 years of hemispheric real data. The verification using our formula in Mexico, showed better results than the one using the statistical formula.
\end{abstract}

Key words. Meteorology and atmospheric dynamics (climatology; convective processes; general circulation).

\section{Introduction}

The objective of this work is to obtain a parametrization of the precipitation anomalies, as a linear function of the surface temperature and the $700 \mathrm{mb}$ temperature anomalies, in order to improve the prediction in monthly precipitation, using the Adem thermodynamic model (ATM).

The statistical parametrization of the precipitation which has been used in the ATM for the prediction of monthly precipitation in the United States (Adem and Donn, 1981), and in Mexico (Adem et al., 1995), and in climate simulations (Adem, 1996), was derived by Clapp et al. (1965), as a multiple regression equation for

Correspondence to: V. M. Mendoza precipitation. They assumed that the anomaly of the total monthly precipitation can be expressed as a simple linear function of the local anomalies of mean-monthly temperature and the west-east and the south-north wind components at $700 \mathrm{mb}$. These three variables were chosen simply because there are physical reasons for expecting them to be related to precipitation. They assume the following linear regression equation

$R-R_{N}=b\left(T_{7}-T_{7 N}\right)+c\left(U_{7}-U_{7 N}\right)+d\left(V_{7}-V_{7 N}\right)$

where $R$ is the total monthly precipitation (inches); $T_{7}$ the monthly mean temperature $(K)$ at $700 \mathrm{mb}$, and $U_{7}$ and $V_{7}$, the horizontal wind components $\left(\mathrm{m} \mathrm{s}^{-1}\right)$ at $700 \mathrm{mb}$, regarded as positive when from west to east and from south to north, respectively. The subscript $N$ refers to normal or long period averages which, in this study, were the sample means. In order to determine the regression coefficients, $b, c$ and $d$, approximately $12 \mathrm{y}$ of monthly-mean data for 37 land or island stations scattered over the Northern Hemisphere were used. Data for individual stations were extracted from a variety of sources. In the vast areas where there were no measured precipitation figures (mainly over oceans) or where no computations were made, certain reasonable guidelines were followed based on the available calculations and on synoptic experience.

In spite of inadequate data coverage and low correlations, it was concluded that the geographical pattern of the temperature coefficient $(b)$, depends mainly on climate.

The distribution of the wind component coefficients, $c$ and $d$, was assumed to depend mainly on terrain and latitude. Where westerly or southerly wind is directed from water to land and especially if it is forced to ascend mountains, a strong positive relationship between rainfall and wind is found, (demonstrated in Negri et al., 1993). When it is directed downslope, these components are negatively related to rainfall. The south-north wind component, $V$, tends to be positively related to rainfall almost everywhere due to the observed fact that convergence and rising motion prevails with southerly winds and the opposite with northerly wind. 
Equation (1) had to be modified in order to be used in the ATM because the latter predicts the mean temperature in mid-troposphere (approximately $500 \mathrm{mb}$ ) and not the winds. The mid-tropospheric temperature anomalies can be used directly in the first term on the right of Eq. (1), assuming there is little difference in the anomaly of monthly mean temperature at 500 and $700 \mathrm{mb}$. However, the two terms involving the winds must be transformed in two important respects. First, the predictions are made for the NMC grid, which is a grid array of 1977 points on a polar-stereographic projection over the Northern Hemisphere, whose $X$ axis points along the $10^{\circ} \mathrm{E}$ meridian and $Y$ axis along the $80^{\circ} \mathrm{W}$ meridian (Fig. 1). Therefore, it is necessary to transform the eastward $(U)$ and northward $(V)$ wind components to the corresponding components $U^{\prime}$ and $V^{\prime}$, directed along the positive $X$ and $Y$ axes respectively by a simple transformation of coordinates. The second transformation is to convert the wind into a thermal wind (a measure of vertical wind shear), so that the wind components at $700 \mathrm{mb}$ can be replaced by temperature gradients in mid-troposphere. The details of these transformations are not documented here.

Finally, the rainfall $(R)$ in inches per month may be expressed in terms of the heat released by condensation $\left(G_{5}\right)$ in the atmosphere $\left(\mathrm{cal} \mathrm{cm}^{-2} \mathrm{day}^{-1}\right.$ $\approx 0.484 \mathrm{~W} \mathrm{~m}^{-2}$ ), by multiplying $R$ in $\mathrm{cm} \mathrm{day}^{-1}$ by the latent heat of condensation $(L)$ in $\mathrm{cal} \mathrm{g}^{-1}$ and by the water density $\rho_{w}$ in $\mathrm{g} \mathrm{cm}^{-3}$.

Using these transformations, Eq (1) becomes:

$$
\begin{gathered}
\left(G_{5}-G_{5 N}\right)_{i, j}=b^{\prime} \\
\left(T_{m D N}\right)_{i, j}+c^{\prime}\left[\left(T_{m D N}\right)_{i, j+1}-\left(T_{m D N}\right)_{i, j-1}\right] \\
+d^{\prime}\left[\left(T_{m D N}\right)_{i+1, j}-\left(T_{m D N}\right)_{i-1, j}\right]
\end{gathered}
$$

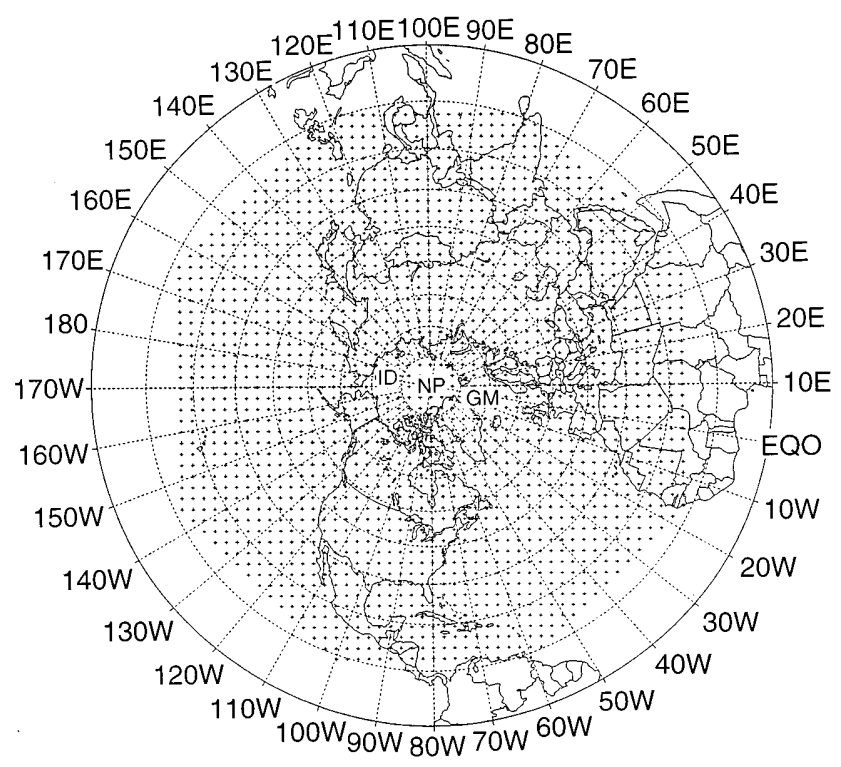

Fig. 1. NMC grid used in the Adem thermodynamic model: 1977 points distributed in a polar stereographic projection where $X$ and $Y$ coordinate axes were arbitrarily determinated along $10^{\circ} \mathrm{E}$ and $80^{\circ} \mathrm{W}$, respectively where $\left(G_{5}-G_{5 N}\right)$ is expressed in cal $\mathrm{cm}^{-2}$ day $^{-1}$; the subscripts $i$ and $j$, are index numbers identifying the $X$ and $Y$ coordinates, respectively, of the NMC grid. $D N$ denotes the departure from normal of mid-tropospheric temperature, $\left(T_{m}-T_{m N}\right)$ in $K$; and the wind components are replaced by temperature gradients in the midtroposphere. Finally, the transformed coefficients $b^{\prime}, c^{\prime}$ and $d^{\prime}$ were determined as functions of the statistical regression coefficients $b, c$ and $d$ interpolated at each grid point.

\section{Theoretical parametrization}

For the parametrization of precipitation we will try to develop a theoretical linear formula similar to Eq. (2), to be used in the ATM and attempt to improve the results in monthly rainfall prediction.

We start with the thermodynamic energy equation which can be expressed as

$\rho^{*} c_{p} \frac{\mathrm{d} T^{*}}{\mathrm{~d} t}-\frac{\mathrm{d} P^{*}}{\mathrm{~d} t}=\dot{Q}_{R}^{*}+\dot{Q}_{s}^{*}+\dot{Q}_{T}^{*}-L \rho^{*} \frac{\mathrm{d} q_{s}^{*}}{\mathrm{~d} t}+\dot{Q_{c c}^{*}}$

where $c_{p}$ is the specific heat at constant pressure of the humid air; $T^{*}, P^{*}$ and $\rho^{*}$ are the three-dimensional fields of temperature, pressure and density; $Q_{R}^{*}$ is the heating rate due to long and shortwave radiation; $\dot{Q}_{s}^{*}$ is the heating rate of sensible heat given off to the atmosphere by vertical turbulent transport and $\dot{Q}_{T}^{*}$ is the heating rate due to the divergence of horizontal turbulent flux of heat. The total heat released by condensation is of two forms (Washington and Williamson, 1977): $-L \rho^{*} \mathrm{~d} q_{s}^{*} / \mathrm{d} t$, referred to as stable latent heat release, where $L$ is the latent heat of vaporization and $q_{s}^{*}$ is the saturated specific humidity. $Q_{c c}^{*}$, is the heat released by precipitation associated with convection cumulus activity which usually dominates over the equator, the tropics and higher latitude continental areas in the summer.

The three-dimensional field of temperature in the atmosphere is expressed by:

$T^{*}=T+\beta(H-z)$

where $\beta$ is the constant lapse rate of the standard atmosphere and $T$ is the temperature of $z=H$, where $H=9 \mathrm{~km}$ is the height of the ATM.

Using Eq. (4) together with the hydrostatic equilibrium and the perfect gas equations we obtain:

$P^{*}=P\left(\frac{T^{*}}{T}\right)^{\alpha}$
$\rho^{*}=\rho\left(\frac{T^{*}}{T}\right)^{\alpha-1}$

where $P$ and $\rho$ are the corresponding values of $P^{*}$ and $\rho^{*}$ at $z=H$, and $\alpha=g / R \beta ; g$ is the gravitational acceleration; and $R$ is the gas constant of humid air.

The saturated specific humidity is given with good degree of approximation by: 
$q_{s}^{*}=0.622 \frac{e_{s}^{*}}{P^{*}}$

where $e_{s}^{*}$ is the saturation water vapor pressure, which is a function of temperature and can be expressed with a simple formula (Adem, 1967a):

$e_{s}^{*}=a_{1}+b_{1} t^{*}+c_{1} t^{* 2}+d_{1} t^{* 3}+l_{1} t^{* 4}$

where $e_{s}^{*}$ is in millibars and $t^{*}=T^{*}-273.16{ }^{\circ} \mathrm{C} ; T^{*}$ is the absolute temperature given by Eq. (4); $a_{1}=6.115$, $b_{1}=0.42915, \quad c_{1}=0.014206, \quad d_{1}=3.046 \times 10^{-4}$ and $l_{1}=3.2 \times 10^{-6}$.

The relative change of the saturation vapor pressure is related to the relative change of temperature by the Clausius - Clapeyron equation:

$\frac{\mathrm{d} e_{s}^{*}}{e_{s}^{*}}=\frac{L}{R_{v}} \frac{\mathrm{d} T^{*}}{T^{* 2}}$

where $R_{v}$ is the gas constant of water vapor.

Using Eqs. (7) and (9) we obtain:

$\frac{1}{q_{s}^{*}} \frac{\mathrm{d} q_{s}^{*}}{\mathrm{~d} t}=\frac{L}{R_{v} T^{* 2}} \frac{\mathrm{d} T^{*}}{\mathrm{~d} t}-\frac{1}{P^{*}} \frac{\mathrm{d} P^{*}}{\mathrm{~d} t}$

By introducing $\mathrm{d} T^{*} / \mathrm{d} t$ from Eq. (3), into Eq. (10), we obtain:

$$
\begin{aligned}
L \rho^{*} \frac{\mathrm{d} q_{s}^{*}}{\mathrm{~d} t}= & \frac{L q_{s}^{*}}{P^{*}}\left(\frac{L P^{*}-\rho^{*} c_{p} R_{v} T^{* 2}}{L^{2} q_{s}^{*}+c_{p} R_{v} T^{* 2}}\right) \frac{\mathrm{d} P^{*}}{\mathrm{~d} t} \\
& +\frac{L^{2} q_{s}^{*}\left(\dot{Q}_{R}^{*}+\dot{Q}_{s}^{*}+\dot{Q}_{T}^{*}+\dot{Q}_{c c}^{*}\right)}{L^{2} q_{s}^{*}+c_{p} R_{v} T^{* 2}}
\end{aligned}
$$

Using the perfect gas equation and the approximation $\mathrm{d} P^{*} / \mathrm{d} t \approx-\rho^{*} g W^{*}$ where $W^{*}$ denotes the vertical component of wind, we obtain the stable latent heat release:

$$
\begin{aligned}
-L \rho^{*} \frac{\mathrm{d} q_{s}^{*}}{\mathrm{~d} t}= & \frac{L \rho^{*} g q_{s}^{*}}{R}\left(\frac{L R-c_{p} R_{v} T^{*}}{L^{2} q_{s}^{*}+c_{p} R_{v} T^{* 2}}\right) W^{*} \delta \\
& -\frac{L^{2} q_{s}^{*}\left(\dot{Q}_{R}^{*}+\dot{Q}_{s}^{*}+\dot{Q}_{T}^{*}+\dot{Q}_{c c}^{*}\right)}{L^{2} q_{s}^{*}+c_{p} R_{v} T^{* 2}} \delta^{\prime}
\end{aligned}
$$

where

$\delta=\left\{\begin{array}{l}1: \text { if } W^{*}>0 \text { and } q^{*} \geq q_{s}^{*} \\ 0: \text { if } W^{*} \leq 0 \text { or } q^{*}<q_{s}^{*}\end{array}\right.$

$\delta^{\prime}=\left\{\begin{array}{l}1: \text { if } q^{*} \geq q_{s}^{*} \\ 0: \text { if } q^{*}<q_{s}^{*}\end{array}\right.$

and where $q^{*}$ is the specific humidity, which can be computed from the conservation of water vapor equation. In Eq. (12), the first term of the right hand side represents the latent heat release by adiabatic ascent of saturated air when $\delta=1$; and the second term represents the latent heat release by non-adiabatic cooling of saturated air when $\delta^{\prime}=1$.

We assume that all water vapor is concentrated below the $500 \mathrm{mb}$ surface; therefore the total heat released by condensation of water vapor $G_{5}$, for a vertical column of $H_{1}$ height at $500 \mathrm{mb}$ and unit area, is obtained integrating the following equation from the surface in $z=h$ to $z=H_{1}$ :

$G_{5}=-\int_{h}^{H_{1}} L \rho^{*} \frac{\mathrm{d} q_{s}^{*}}{\mathrm{~d} t} \mathrm{~d} z+\int_{h}^{H_{1}} \dot{Q}_{c c}^{*} \mathrm{~d} z$

where $h$ is the height of the terrain. Substituting Eq. (12) into Eq. (15) we obtain:

$$
\begin{aligned}
G_{5}= & \frac{g L}{R} \int_{h}^{H_{1}} \delta \rho^{*} q_{s}^{*}\left(\frac{L R-c_{p} R_{v} T^{*}}{L^{2} q_{s}^{*}+c_{p} R_{v} T^{* 2}}\right) W^{*} \mathrm{~d} z \\
& -L^{2} \int_{h}^{H_{1}} \delta^{\prime} q_{s}^{*}\left(\frac{\dot{Q}_{R}^{*}+\dot{Q}_{s}^{*}+\dot{Q}_{T}^{*}+\dot{Q}_{c c}^{*}}{L^{2} q_{s}^{*}+c_{p} R_{v} T^{* 2}}\right) \mathrm{d} z+\int_{h}^{H_{1}} \dot{Q}_{c c}^{*} \mathrm{~d} z
\end{aligned}
$$

A diagnostic formula for the vertical wind, $W^{*}$, has been derived by Adem (1967b), showing that the use of the divergence of geostrophic wind is a good working method for the computations of vertical wind when dealing with average states over periods of a month. In this work, we use Adem's formula for $W^{*}$, with some subsequent modifications carried out by Mendoza (1992), obtaining

$$
W^{*}=\frac{\rho_{a}}{\rho^{*}} W_{E}+\left[g_{1}^{*}-\frac{\rho_{a}}{\rho^{*}} g_{1}\right] J(f, P)+\left[g_{2}^{*}-\frac{\rho_{a}}{\rho^{*}} g_{2}\right] J(f, T)
$$

where

$g_{1}^{*}=\frac{R T^{* 2}}{f^{2} P \beta(\alpha+1)}$

and

$g_{2}^{*}=\frac{g T^{*}}{f^{2} T \beta^{2}}\left(\frac{T}{\alpha}-\frac{T^{*}}{\alpha+1}\right)$

where

$\alpha=\frac{g}{R \beta}$ and $g_{j}=\left(g_{j}^{*}\right)_{z=h}$ with $j=1,2$

$\rho_{a}=\rho^{*}\left(\frac{T_{a}}{T}\right)^{\alpha-1}$

$T_{a}=\beta(H-h)+T$

$\rho_{a}$ and $T_{a}$ given by Eqs. (18) and (19) are the density and the temperature at $z=h$, respectively. In Eq. (17), the terms of the Jacobians $J(f, P)$ and $J(f, T)$ correspond to the divergence of geostrophic wind and $W_{E}=\left(W^{*}\right)_{z=h}$ given by

$W_{E} \approx W_{a}+\frac{1}{\rho_{a} f}\left(\widehat{k} \cdot \nabla \times \tau_{a}\right)$

is the vertical wind at the surface, which is approximated as the vertical wind emerging from the Ekman layer to the free atmosphere. $W_{a}$ is the vertical surface wind 
induced by the terrain slope, which plays a key role in defining the local main rain features (Negri et al., 1993) and $\tau_{a}$ is the surface stress. $W_{a}$ is given by

$W_{a}=\vec{V}_{a} \cdot \nabla h$

where $\vec{V}_{a}$ is the horizontal surface wind. The component along the $Z$ axis (pointing toward the local zenith) of the rotational of surface stress, can be approximated by

$\widehat{k} \cdot \nabla \times \tau_{a}=\rho_{a} C_{D}\left|\vec{V}_{a N}\right|\left(\frac{\partial v_{a}}{\partial x}-\frac{\partial u_{a}}{\partial y}\right)$

where $C_{D}=1.5 \times 10^{-3}$ is the drag coefficient of the wind, (Kasahara and Washington, 1967). $\left|\vec{V}_{a N}\right|$ is the normal value of the horizontal surface wind speed taken from ATM climatological files; $u_{a}$ and $v_{a}$ are the $X$ and $Y$ components of the horizontal surface wind, respectively, where the directions of the horizontal coordinates axes are arbitrarily chosen.

In Eqs. (21) and (22), $\vec{V}_{a}$ is assumed to be a geostrophic wind. Therefore, in order to obtain its components we use the three-dimensional geostrophic wind for a layer of height $H$ with a constant lapse rate, obtaining:

$u^{*}=-\frac{R}{f}\left[\frac{T^{*}}{T}+\alpha\left(1-\frac{T^{*}}{T}\right)\right] \frac{\partial T}{\partial y}-\frac{R T^{*}}{f \rho} \frac{\partial \rho}{\partial y}$

$v^{*}=\frac{R}{f}\left[\frac{T^{*}}{T}+\alpha\left(1-\frac{T^{*}}{T}\right)\right] \frac{\partial T}{\partial x}-\frac{R T^{*}}{f \rho} \frac{\partial \rho}{\partial x}$

According to Adem (1967b), the contribution of the terms containing $\partial \rho / \partial x$ and $\partial \rho / \partial y$ in formulas (23) and (24) is negligibly small compared with the terms containing $\partial T / \partial x$ and $\partial T / \partial y$. Therefore, evaluating the components $u^{*}$ and $v^{*}$ for $z=h$, we obtain

$u_{a}=-\frac{R_{s}}{f} \frac{\partial T}{\partial y}$

$v_{a}=\frac{R_{s}}{f} \frac{\partial T}{\partial x}$

where

$R_{s}=R\left[\frac{T_{a}}{T}+\alpha\left(1-\frac{T_{a}}{T}\right)\right]$

Substituting Eqs. (25) and (26) into Eqs. (21) and (22), and the resulting expressions in Eq. (20), we obtain:

$W_{E}=-\frac{R_{s}}{f} J(h, T)+\frac{C_{D}\left|\vec{V}_{a N}\right|}{f^{2}} R_{s} \nabla^{2} T$

Using the approximation $J(f, P) \approx \rho R J(f, T)=$ $(P / T) J(f, T)$, and Eq. (28) into Eq. (17), we obtain:

$$
\begin{aligned}
W^{*}= & -\frac{\rho_{a}}{\rho^{*}} \frac{R_{s}}{f} J(h, T) \\
& +\left[\frac{P}{T}\left(g_{1}^{*}-\frac{\rho_{a}}{\rho^{*}} g_{1}\right)+\left(g_{2}^{*}-\frac{\rho_{a}}{\rho^{*}} g_{2}\right)\right](f, T)
\end{aligned}
$$

\section{The heating rates}

The heating rate due to radiation, $\dot{Q}_{R}^{*}$, is given by Adem, (1968b) as

$\dot{Q}_{R}^{*}=\frac{E_{T}}{H}$

where $E_{T}$ is the excess of radiation in the layer of depth $H$ and is parametrized by the formula (Adem, 1964):

$E_{T}=F_{30}+F_{30}^{\prime} \varepsilon+F_{31} T^{\prime}+\left(F_{32}+F_{32}^{\prime} \varepsilon_{N}\right) T_{s}^{\prime}+\left(a_{2}+b_{3} \varepsilon\right) I$

where $F_{30}, F_{30}^{\prime}, F_{31}, F_{32}$ and $F_{32}^{\prime}$ are constants; $a_{2}$ and $b_{3}$, are climatological functions of latitude and season, obtained in Adem, (1964); $I$ is the mean monthly solar radiation, which is computed from Milankovich formula; $T^{\prime}=T-T_{0}$ and $T_{s}^{\prime}=T_{s}-T_{s 0}$ are the departures from $T$ (the mean temperature at $z=H$ ), and $T_{s}$ (the mean surface temperature), and $T^{\prime} \ll T_{0}$, and $T_{s}^{\prime} \ll T_{s 0}$, respectively, where $T_{0}=229.5 \mathrm{~K}$ and $T_{s 0}=288 \mathrm{~K}$ are constants; $\varepsilon$ is the fractional cloud cover and $\varepsilon_{N}$ is the corresponding normal value (taken from ATM climatological files).

The fractional cloud cover is given by (Clapp et al., 1965):

$\varepsilon=\varepsilon_{N}+d_{2}\left(G_{5}-G_{5 N}\right)$

where $d_{2}=6.959 \times 10^{-3} \mathrm{~W}^{-1} \mathrm{~s}$ is the empirical constant between the anomalies of cloudiness and the heat released by condensation of water vapor, $G_{5}$.

The heating rate of sensible heating added to the atmosphere by vertical turbulent transport, $Q_{s}^{*}$, is given by Adem (1968b), as

$\dot{Q}_{s}^{*}=\frac{G_{2}}{H}$

where $G_{2}$ is the sensible heating given off to the atmospheric layer of depth $H$, by vertical turbulent transport which was parametrized by Clapp et al., (1965) and is expressed as

$$
\begin{aligned}
G_{2}= & G_{2 N}+\left|\vec{V}_{a N}\right|\left[G_{2}^{\prime \prime} K_{2}+\left(1-G_{2}^{\prime \prime}\right) K_{3}\right]\left[\left(T_{s}^{\prime}-T_{s N}^{\prime}\right)\right. \\
& \left.-\left(T^{\prime}-T_{N}\right)\right]
\end{aligned}
$$

where

$G_{2}^{\prime \prime}= \begin{cases}1, & \text { for oceans } \\ 0, & \text { for continents }\end{cases}$

$K_{2}$ and $K_{3}$ are constant parameters and $G_{2 N}, T_{s N}^{\prime}$ and $T_{N}^{\prime}$ are the normal values of $G_{2}, T_{s}^{\prime}$ and $T^{\prime}$, respectively (Adem, 1965).

The heating rate due to the divergence of horizontal turbulent flux, can be written by (Mendoza, 1992):

$\dot{Q}_{T}^{*}=c_{p} \rho^{*} \mathscr{K} \nabla^{2} T^{*}$

where $c_{p}$ is the specific heat at constant pressure, $\rho^{*}$ is given by Eq. (6), and $T^{*}$ by Eq. (4); and $\mathscr{K}$ is the Austausch coefficient.

The heating rate per unit volume due to the heat released by precipitation associated to convection 
cumulus activity was parametrized by Kuo (1965) with the following formula:

$\dot{Q}_{c c}^{*}=\frac{(a r) c_{p}\left(T_{m a}^{*}-T^{*}\right)}{\Delta t}$

where $(a r)$ is a parameter without dimension, related to the area covered by convection cumulus; $\Delta t$ the lifetime parameter of convection (30 min); $T_{m a}^{*}>T^{*}$, the three dimensional temperature along the moist adiabat which passes through the lifting condensation level.

For this work, we use the following crude approximation:

$\dot{Q}_{c c}^{*}=\frac{A_{0}}{H}\left(T_{m a}-T_{m}\right)$

where $T_{m a}$ is the moist adiabat temperature at $z=H / 2$, and $T_{m}=\beta H / 2+T$ is the temperature $T^{*}$ in $z=H / 2$; and $A_{0}$ is given by:

$A_{0}=\frac{\rho_{m} c_{p} H}{\Delta t}(a r)_{\phi}$

where $\rho_{m}=\rho^{*}$ at $z=H / 2$. For average states over periods of a month or a season, we assume that $(a r)_{\phi}$ is a Gauss function of latitude given by:

$(a r)_{\phi}=(a r)_{0} \exp \left[-\gamma\left(\phi-\phi_{0}\right)^{2}\right]$

where $\phi$ is the latitude angle and $\phi_{0}=0^{\circ}$ at winter and spring and $\phi_{0}=10^{\circ}$ at summer and fall. In expression (39), we assume that convection cumulus activity dominates around the equatorial zone. We prescribe $(a r)_{0}=(a r)_{\phi=\phi_{0}}=0.025$ and $\gamma=8.2 \times 10^{-4}$ is an empirical parameter which is used when $\phi$ is given in degrees. Washington and Williamson (1977), assume that $(a r)=1$ if the lower layers become supersaturated, and Krishnamurti (1969), suggests that $(a r) \leq 0.01$.

\section{The linear equation}

Using Eqs. (29), (30), (33), (35) and (37) into Eq. (16), and substituting the integration variable by $\mathrm{d} z=-(1 / \beta) \mathrm{d} T^{*}$, (Adem, 1968a), we obtain:

$$
\begin{aligned}
G_{5}= & \frac{I_{1}}{f} J(h, T)+\left[\frac{P}{T} I_{2}+I_{3}\right] J(f, T) \\
& +\left(g \frac{c_{D}\left|\vec{V}_{a N}\right|}{f^{2}} I_{4}+\mathscr{K} I_{6}\right) \nabla^{2} T \\
& +I_{5}\left[E_{T}+G_{2}+A_{0}\left(T_{m a}-T_{m}\right)\right] \\
& +\left(\frac{H_{1}-h}{H}\right) A_{0}\left(T_{m a}-T_{m}\right)
\end{aligned}
$$

where

$$
\begin{aligned}
& I_{1}=\frac{g L R_{s}}{R \beta} \int_{T_{a}}^{T_{1}} \rho_{a} q_{s}^{*}\left(\frac{L R-c_{p} R_{v} T^{*}}{L^{2} q_{s}^{*}+c_{p} R_{v} T^{* 2}}\right) \delta \mathrm{d} T^{*} \\
& I_{2}=-\frac{g L}{R \beta} \int_{T_{a}}^{T_{1}} \rho^{*} q_{s}^{*}\left(\frac{L R-c_{p} R_{v} T^{*}}{L^{2} q_{s}^{*}+c_{p} R_{v} T^{* 2}}\right)\left(g_{1}^{*}-\frac{\rho_{a}}{\rho^{*}} g_{1}\right) \delta \mathrm{d} T^{*}
\end{aligned}
$$

$I_{3}=-\frac{g L}{R \beta} \int_{T_{a}}^{T_{1}} \rho^{*} q_{s}^{*}\left(\frac{L R-c_{p} R_{v} T^{*}}{L^{2} q_{s}^{*}+c_{p} R_{v} T^{* 2}}\right)\left(g_{2}^{*}-\frac{\rho_{a}}{\rho^{*}} g_{2}\right) \delta \mathrm{d} T^{*}$

$I_{4}=-\frac{L R_{s}}{R \beta} \int_{T_{a}}^{T_{1}} \rho_{a} q_{s}^{*}\left(\frac{L R-c_{p} R_{v} T^{*}}{L^{2} q_{S}^{*}+c_{p} R_{v} T^{* 2}}\right) \delta \mathrm{d} T^{*}$

$I_{5}=\frac{L^{2}}{\beta H} \int_{T_{a}}^{T_{1}}\left(\frac{q_{s}^{*}}{L^{2} q_{s}^{*}+c_{p} R_{v} T^{* 2}}\right) \delta^{\prime} \mathrm{d} T^{*}$

$I_{6}=\frac{L^{2} C_{p}}{\beta} \int_{T_{a}}^{T_{1}}\left(\frac{\rho^{*} q_{s}^{*}}{L^{2} q_{s}^{*}+c_{p} R_{v} T^{* 2}}\right) \delta^{\prime} \mathrm{d} T^{*}$

where $T_{1}$ is the temperature at $500 \mathrm{mb}$, and $T_{a}$ is given by Eq. (19).

Since we will use $500 \mathrm{mb}$ data to compute the integrals (41), $P, T$ and $\rho$ can be computed applying Eqs. (4) and (5) at $z=H_{1}$ (500 mb height). Therefore, we obtain

$$
\begin{aligned}
P & =(500 \mathrm{mb})\left[\frac{T_{1}-\beta\left(H-H_{1}\right)}{T_{1}}\right]^{\alpha} \\
T & =T_{1}-\beta\left(H-H_{1}\right)
\end{aligned}
$$

Furthermore, $\rho$ is computed from the perfect gas equation:

$\rho=P / R T$

Using $P, T$ and $\rho$ for $500 \mathrm{mb}$, we can compute $\rho_{a}$ and $T_{a}$ from Eqs. (18) and (19) respectively. The saturated specific humidity in the integrals (41) is given by Eq. (7), where the saturation vapor pressure is computed from Eq. (8) and the pressure $P^{*}$ from Eq. (5). The density $\rho^{*}$ is computed from Eq. (6). $R_{s}$ is a function of $T_{a}$ and $T$, given by Eq. (27).

Finally the values of $\beta, C_{D}, g, L, R$ and $R_{v}$, together with other values of parameter used in this work are shown in Table 1.

In order to obtain a linear formula for the anomalies of $G_{5}$ similar to Clapp et al.'s (1965) Eq. (2), we have used normal values for the coefficient of

Table 1. Model parameters

\begin{tabular}{llll}
\hline & Symbol & Value & Units \\
\hline Lapse rate & $\beta$ & $6.5 \times 10^{-3}$ & $\mathrm{Km}^{-1}$ \\
Drag coefficient & $C_{D}$ & $1.5 \times 10^{-3}$ & \\
Gravitational acceleration & $g$ & 9.8 & $\mathrm{~ms}^{-2}$ \\
Gas constant & $R$ & 287.05 & $\mathrm{Jkg}^{-1} \mathrm{~K}^{-1}$ \\
$\begin{array}{l}\text { Vapor gas constant } \\
\text { Convection cumulus latent }\end{array}$ & $R_{v}$ & 461 & $\mathrm{Jkg}^{-1} \mathrm{~K}^{-1}$ \\
$\quad \begin{array}{l}\text { heat release parameters } \\
\text { Austausch coefficient }\end{array}$ & $(a r)_{0}$ & $0.2 \times 10^{-4}$ & \\
$\begin{array}{l}\text { Vaporization latent } \\
\text { heat constant }\end{array}$ & $L$ & 2.025 & \\
$\begin{array}{l}\text { Specific heat at } \\
\text { constant pressure }\end{array}$ & $c_{p}$ & 1.004 & $\mathrm{JK}^{-1}$ \\
$\begin{array}{l}\text { Cloudiness parameter } \\
\text { Parameter of the sensible heat }\end{array}$ & $d_{2}=K_{3}$ & 2.684 & $\mathrm{~ms}^{-1}$ \\
\hline
\end{tabular}


$J(h, T), J(f, T), \nabla^{2} T, E_{T}, G_{2}$ and $\left(T_{m a}-T_{m}\right)$ in Eq. (40). In agreement with conditions (13) and (14), theoretically $\delta$ and $\delta^{\prime}$ can be determined from a diagnostic formula for the vertical wind $\left(W^{*}\right)$, and from the conservation of water vapor equation. However since these equations are not contained explicitly in ATM, it is not possible to use this procedure. Therefore we have assumed arbitrarily $\delta=\delta^{\prime}=1$ in the integrals (41). This procedure could overvalue the precipitation in subsidence zones and/ or relative humidity below $100 \%$. Taking into account these considerations, we have

$$
\begin{aligned}
G_{5}-G_{5 N}= & \frac{I_{1 N}}{f} J\left(h, T^{\prime}-T_{N}^{\prime}\right) \\
& +\left(\frac{P_{N}}{T_{N}} I_{2 N}+I_{3 N}\right) J\left(f, T^{\prime}-T_{N}^{\prime}\right) \\
& +\left(g \frac{c_{D}\left|\vec{V}_{a N}\right|}{f^{2}} I_{4 N}+\mathscr{K} I_{6 N}\right) \nabla^{2}\left(T^{\prime}-T_{N}^{\prime}\right) \\
& +I_{5 N}\left[\left(E_{T}-E_{T N}\right)+\left(G_{2}-G_{2 N}\right)\right] \\
& -\left[I_{5 N}+\left(\frac{H_{1}-h}{H_{0}}\right)\right] A_{0}\left(T^{\prime}-T_{N}^{\prime}\right)
\end{aligned}
$$

where the subscript $N$ refers to normal or long period average values. In Eq. (45) we have assumed that the anomalies of $T_{m a}$ are negligibly small, and have used, according to Eq. (4),

$T_{m}=\frac{\beta H}{2}+T=\frac{\beta H}{2}+\left(T_{0}+T^{\prime}\right)$.

Therefore $T_{m}^{\prime}=T^{\prime} \quad$ and $\quad T_{m}^{\prime}-T_{m N}^{\prime}=T^{\prime}-T_{N}^{\prime} \quad$ where $T_{m}^{\prime}=T_{m}-T_{m 0}$, with $T_{m 0}=\beta H / 2+T_{0}$.

Using Eqs. (31), (32) and (34) in Eq. (45) we obtain the following linear formula:

$$
\begin{aligned}
\left(G_{5}-G_{5 N}\right)_{i, j}= & a^{\prime \prime}\left(T_{s}^{\prime}-T_{s N}^{\prime}\right)_{i, j}+b^{\prime \prime}\left(T^{\prime}-T_{N}^{\prime}\right)_{i, j} \\
& +c^{\prime \prime} \frac{\partial}{\partial Y}\left(T^{\prime}-T_{N}^{\prime}\right)_{i, j}+d^{\prime \prime} \frac{\partial}{\partial X}\left(T^{\prime}-T_{N}^{\prime}\right)_{i, j} \\
& +e^{\prime \prime} \nabla^{2}\left(T^{\prime}-T_{N}^{\prime}\right)_{i, j}
\end{aligned}
$$

where subscripts $i$ and $j$, are index numbers identifying the $X$ and $Y$ map coordinates of a point in the NMC grid. Taking $T^{\prime}-T_{N}^{\prime}=T_{D N}^{\prime}$, in Eq. (46), we obtain

$$
\begin{aligned}
\frac{\partial}{\partial X} T_{D N i, j}^{\prime}= & T_{D N i+1, j}^{\prime}-T_{D N i-1, j}^{\prime} \\
\frac{\partial}{\partial Y} T_{D N i, j}^{\prime}= & T_{D N i, j+1}^{\prime}-T_{D N i, j-1}^{\prime} \\
\nabla^{2} T_{D N i, j}^{\prime}= & T_{D N i-1, j}^{\prime}+T_{D N i, j+1}^{\prime} \\
& +T_{D N i+1, j}^{\prime}+T_{D N i, j-1}^{\prime}-4 T_{D N i, j}^{\prime}
\end{aligned}
$$

The coefficients in Eq. (46) are given by:

$$
\begin{aligned}
& a^{\prime \prime}=\frac{I_{5 N}}{1-\lambda_{N}}\left[F_{32}+F_{32}^{\prime} \varepsilon_{N}+\left(G_{2}^{\prime \prime} K_{2}+\left(1-G_{2}^{\prime \prime}\right) K_{3}\right)\left|\vec{V}_{a N}\right|\right] \\
& b^{\prime \prime}=\frac{I_{5 N}}{1-\lambda_{N}}\left[F_{31}-\left(G_{2}^{\prime \prime} K_{2}+\left(1-G_{2}^{\prime \prime}\right) K_{3}\right)\left|\vec{V}_{a N}\right|-A_{0}\right]
\end{aligned}
$$

$$
\begin{aligned}
& -\frac{1}{1-\lambda_{N}}\left(\frac{H_{1}-h}{H} A_{0}\right) \\
c^{\prime \prime}= & \frac{1}{1-\lambda_{N}}\left[f_{x}\left(\frac{P_{N}}{T_{N}} I_{2 N}+I_{3 N}\right)+\frac{I_{1 N} h_{x}}{f}\right] \frac{M^{2}}{4 D^{2}} \\
d^{\prime \prime}= & \frac{1}{1-\lambda_{N}}\left[f_{y}\left(\frac{P_{N}}{T_{N}} I_{2 N}+I_{3 N}\right)-\frac{I_{1 N} h_{y}}{f}\right] \frac{M^{2}}{4 D^{2}} \\
e^{\prime \prime}= & \frac{1}{1-\lambda_{N}}\left(\frac{g C_{D}\left|\vec{V}_{a N}\right|}{f^{2}} I_{4 N}+\mathscr{K} I_{6 N}\right) \frac{M^{2}}{D^{2}}
\end{aligned}
$$

and

$\lambda_{N}=I_{5 N}\left(F_{30}^{\prime}+b_{3} I\right) d_{2}$

The coefficient $a^{\prime \prime}$ contains terms of longwave radiation heating and sensible heating which are the surface temperature coefficients in Eqs. (31) and (34).

The terms contained in $b^{\prime \prime}$ are the heating generated by longwave radiation, sensible heating and latent heating release in convection cumulus activity; they are the coefficients of $700 \mathrm{mb}$ temperature in Eqs. (31), (34) and (37). $a^{\prime \prime}$ and $b^{\prime \prime}$ are coefficients related to the second term in Eq. (12), therefore the first and the second terms of the right side of Eq. (46) represents the latent heat release by non-adiabatic cooling of saturated air.

The coefficients $c^{\prime \prime}$ and $d^{\prime \prime}$ are related to the first and second terms of the right side of the vertical wind Eq. (29); and therefore, the third and the fourth terms in the right side of Eq. (46), represents the anomalies of precipitation due to the latent heat of saturated air induced by the terrain slope and by the divergence of geostrophic wind.

The coefficient $e^{\prime \prime}$, contains the drag coefficient $C_{D}$ and the Austausch coefficient $\mathscr{K}$; therefore, the last term in the right side of Eq. (46) represents the anomalies of precipitation due to the latent heat release by adiabatic ascent of saturated air induced by surface friction, plus the latent heat release by non-adiabatic cooling of saturated air due to the divergence of horizontal turbulent flux.

The shortwave radiation heating is included in the second term of the right side of the $\lambda_{N}$ equation so it is included in all coefficients.

In the coefficients $c^{\prime \prime}, d^{\prime \prime}$ and $e^{\prime \prime}, M$ is the map factor in a polar stereographic projection:

$M=\frac{2}{1+\sin \phi}$

where $\phi$ is the latitude angle, $D$ is the distance between consecutive points, $f_{x}=\partial f / \partial X, \quad f_{y}=\partial f / \partial Y$, $h_{x}=\partial h / \partial X$, and $h_{y}=\partial h / \partial Y$, and where

$$
\begin{aligned}
& \frac{\partial f_{i, j}}{\partial X}=f_{i+1, j}-f_{i-1, j} ; \frac{\partial f_{i, j}}{\partial Y}=f_{i, j+1}-f_{i, j-1} \\
& \frac{\partial h_{i, j}}{\partial X}=h_{i+1, j}-h_{i-1, j} ; \frac{\partial h_{i, j}}{\partial Y}=h_{i, j+1}-h_{i, j-1}
\end{aligned}
$$




\section{Numerical results}

We assume that the statistical parametrization (Clapp et al., 1965), which was developed using observed rainfall, temperature and wind data and where the coefficients $b, c$ and $d$ were determinated by multiple correlation in a linear equation, is a good comparative equation to test our theoretical parametrization.
The coefficients $b^{\prime}, c^{\prime}$ and $d^{\prime}$ from Eq. (2) were determinated as functions of the former $b, c$ and $d$. We computed those coefficients and our $b^{\prime \prime}, c^{\prime \prime}$ and $d^{\prime \prime}$ from Eq. (46), in the NMC grid (Fig. 1), using mean-monthly normal values of temperature and height at $500 \mathrm{mb}$, obtained from the National Center of Atmospheric Research, (NCAR NMC Grid Point Data Set, CDROM) in winter and summer.
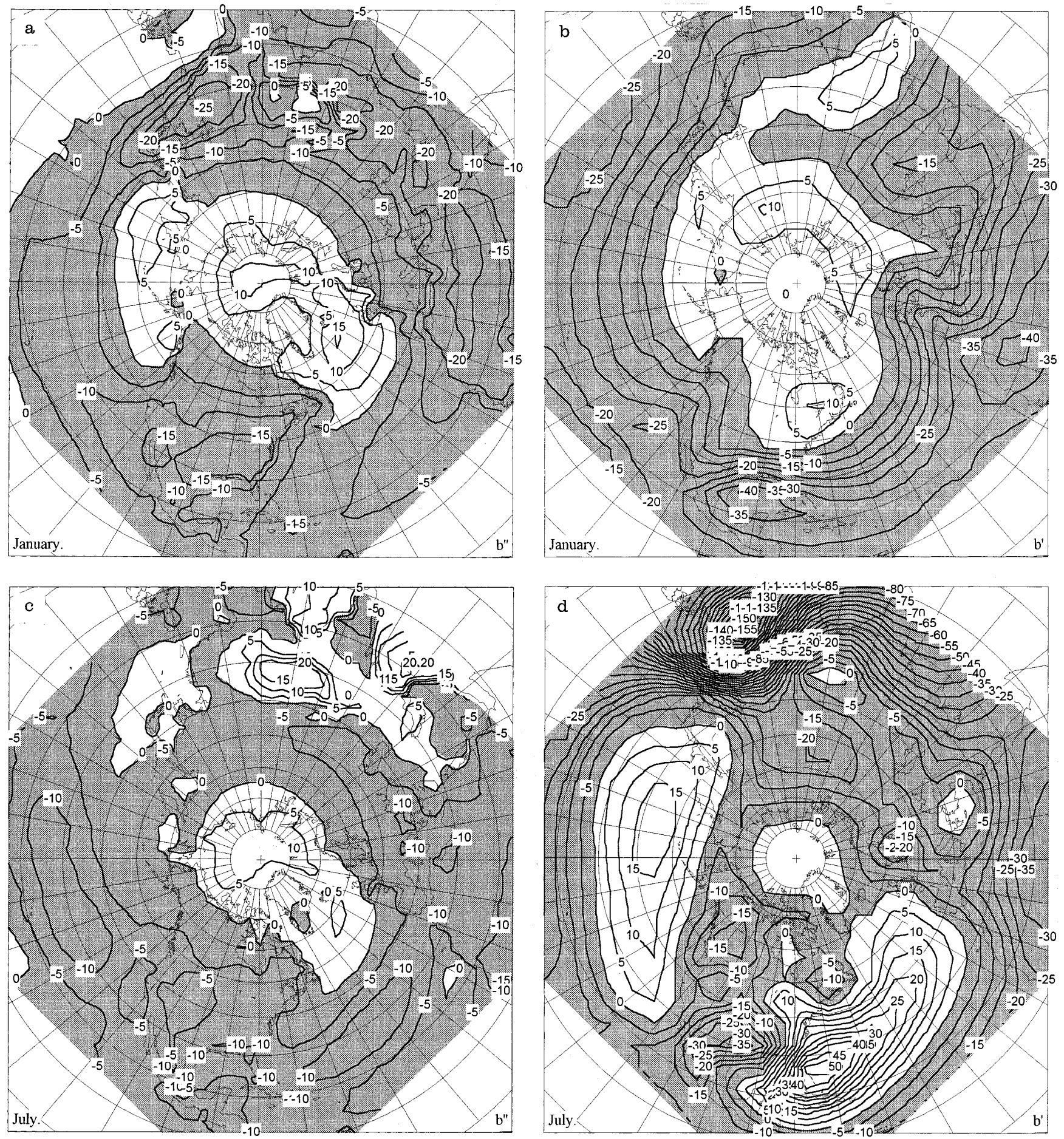

Fig. 2a-d. Geographical patterns of the $b^{\prime \prime}$ coefficient in the theoretical Eq. (46), and the $b^{\prime}$ coefficient in the Clapp et al. (1965) formula, computed in $2 \mathrm{Wm}^{-2} \mathrm{~K}^{-1}$. a is the $b^{\prime \prime}$ coefficient for winter, $\mathbf{b}$ the $b^{\prime}$ coefficient for winter, $\mathbf{c}$ the $b^{\prime \prime}$ coefficient for summer, and $\mathbf{d}$ the $b^{\prime}$ coefficient for summer 
The maps for the coefficients $b^{\prime \prime}$ and $b^{\prime}$ are shown in the Fig. 2a,b for January (winter), respectively, and for July (summer) in Fig. 2c,d, respectively.

The comparison of Fig. 2a,b shows some similarities in signs and magnitudes of the coefficients $b^{\prime \prime}$ and $b^{\prime}$ for winter; however, in summer they are quite different especially in ocean areas. We computed the correlation coefficient $(r)$, between $b^{\prime \prime}$ and $b^{\prime}$ fields and it is 0.62 for winter and 0.04 for summer.
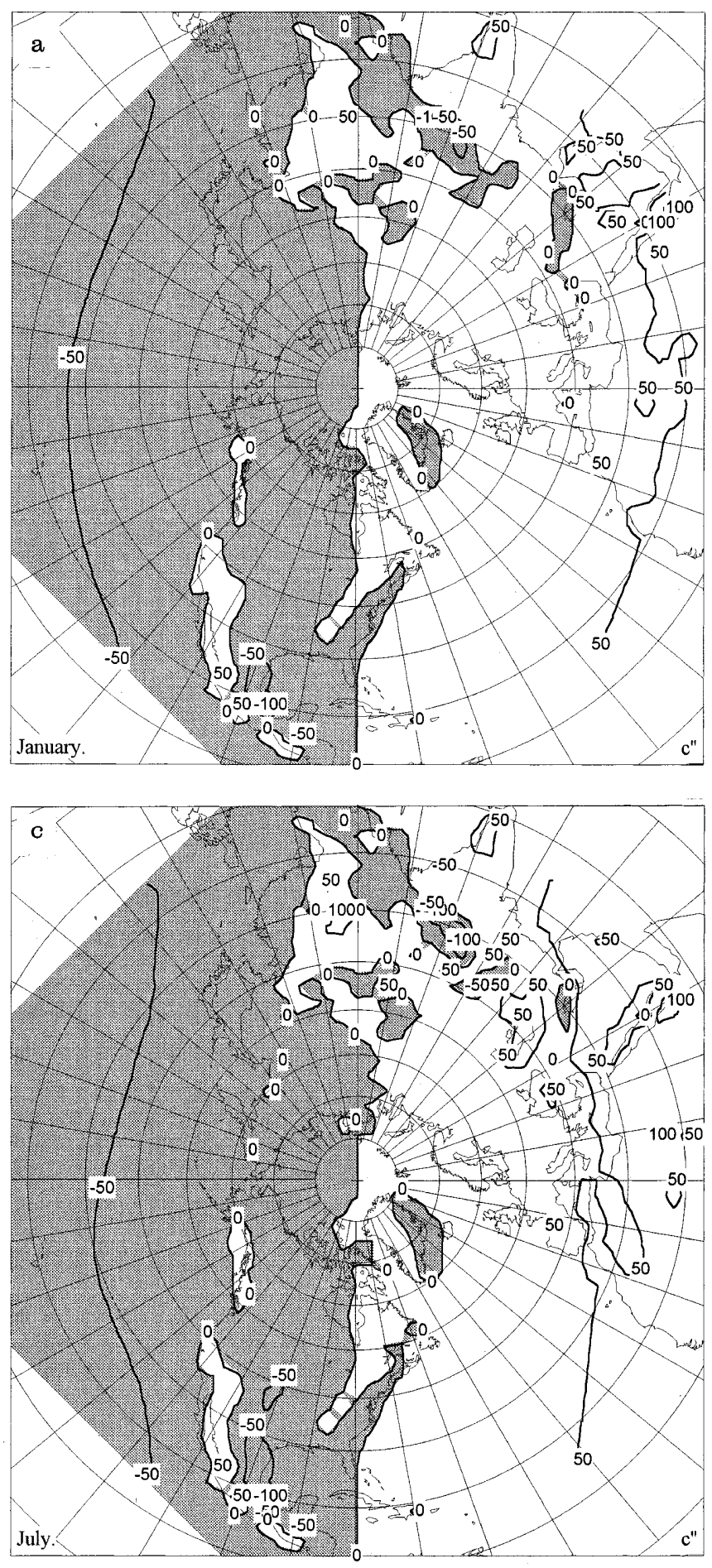

In accordance with Fig. 2a,c, and the term $b^{\prime \prime}\left(T^{\prime}-T_{N}^{\prime}\right)$ in Eq. (46), above normal precipitation tends to occur with above normal temperature $\left[\left(T^{\prime}-T_{N}^{\prime}\right)>0\right]$ in high latitudes and with below normal temperature $\left[\left(T^{\prime}-T_{N}^{\prime}\right)<0\right]$ at lower latitudes in winter and summer, except in the summer over the Arabian Sea, the Gulf of Bengal and the Tibet Plateau, where the above normal precipitation tends to occur with above normal temperature.
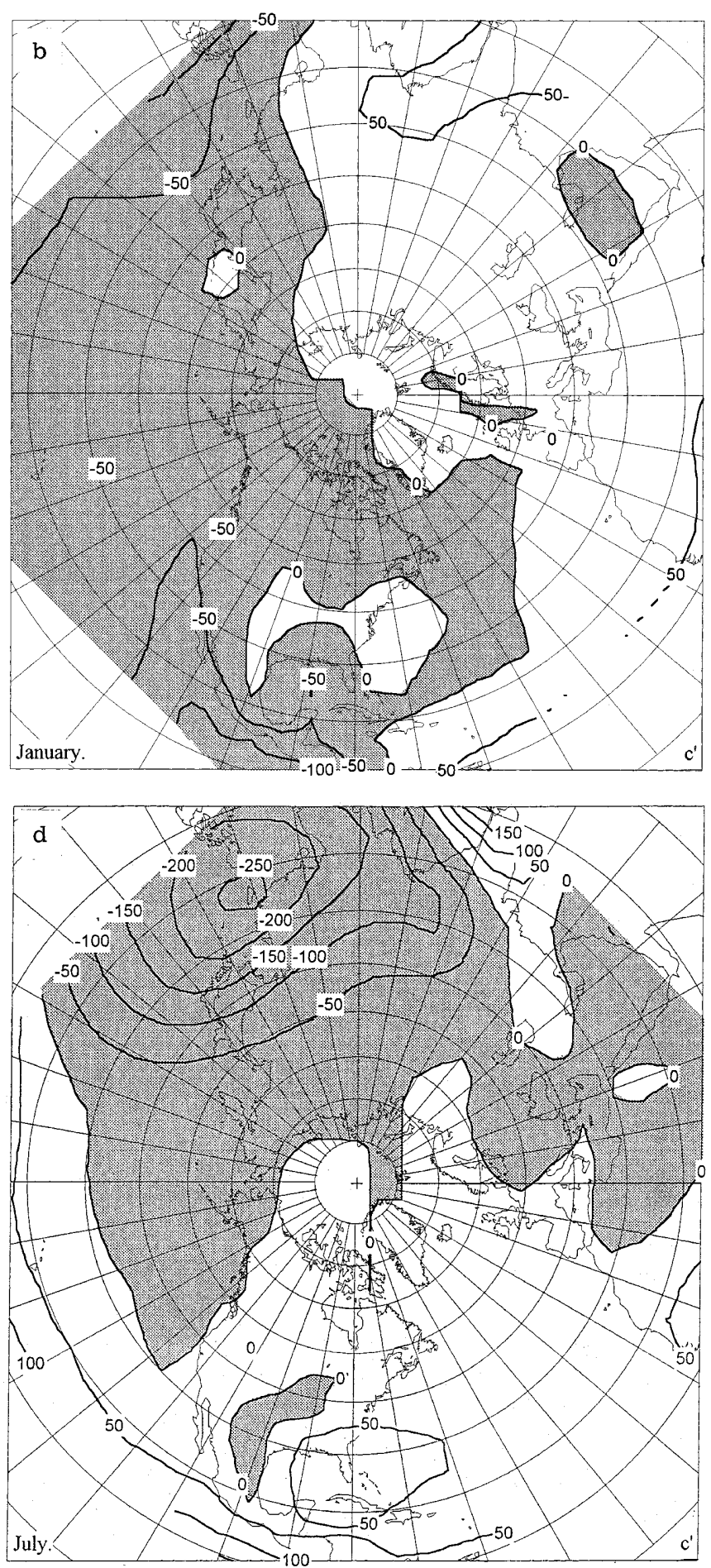

Fig. 3a-d. Geographical patterns of the $c^{\prime \prime}$ coefficient in the theoretical Eq. (46), and the $c^{\prime}$ coefficient, in the Clapp et al. (1965) formula computed in $2 \mathrm{Wm}^{-2} \mathrm{~K}^{-1}$. a Is the $c^{\prime \prime}$ coefficient for winter, $\mathbf{b}$ the $c^{\prime}$ coefficient for winter, $\mathbf{c}$ the $c^{\prime \prime}$ coefficient for summer, and $\mathbf{d}$ the $c^{\prime}$ coefficient for summer 
The maps for the $c^{\prime \prime}, c^{\prime}, d^{\prime \prime}$ and $d^{\prime}$ coefficients are shown for January (winter), in Figs. 3a, 3b, 4a and 4b, respectively, and for July (summer) in Figs. 3c, 3d, 4c and $4 \mathrm{~d}$, respectively.

From the geographic distribution of the coefficients $c^{\prime}$ and $d^{\prime}$, Clapp et al. (1965) concluded that these coefficients depend mainly on terrain and latitude. Looking at our $c^{\prime \prime}, d^{\prime \prime}$ winter maps, (Figs. 3a, 4a), there is a zero line crossing the map vertically in the case of $c^{\prime \prime}$, and crossing the map horizontally in the case of $d^{\prime \prime}$. Due to the fact that the Coriolis parameter depends only on the latitude, the derivatives of $\left(f_{x}\right)_{i, j}=f_{i+1, j}-f_{i-1, j}$ at the grid points over the $Y$ axis $\left(80^{\circ} \mathrm{W}\right)$ are zero; similarly, the derivatives of $\left(f_{y}\right)_{i, j}=f_{i, j+1}-f_{i, j-1}$ at the grid points over the $X$ axis $\left(10^{\circ} \mathrm{E}\right)$ are zero. It can be seen in the maps of Figs. 3a and $4 \mathrm{a}$ where the zero isoline is along the $Y$ and $X$ axes, respectively, with the exception of regions where orographic slope $h_{x}$ and $h_{y}$ is
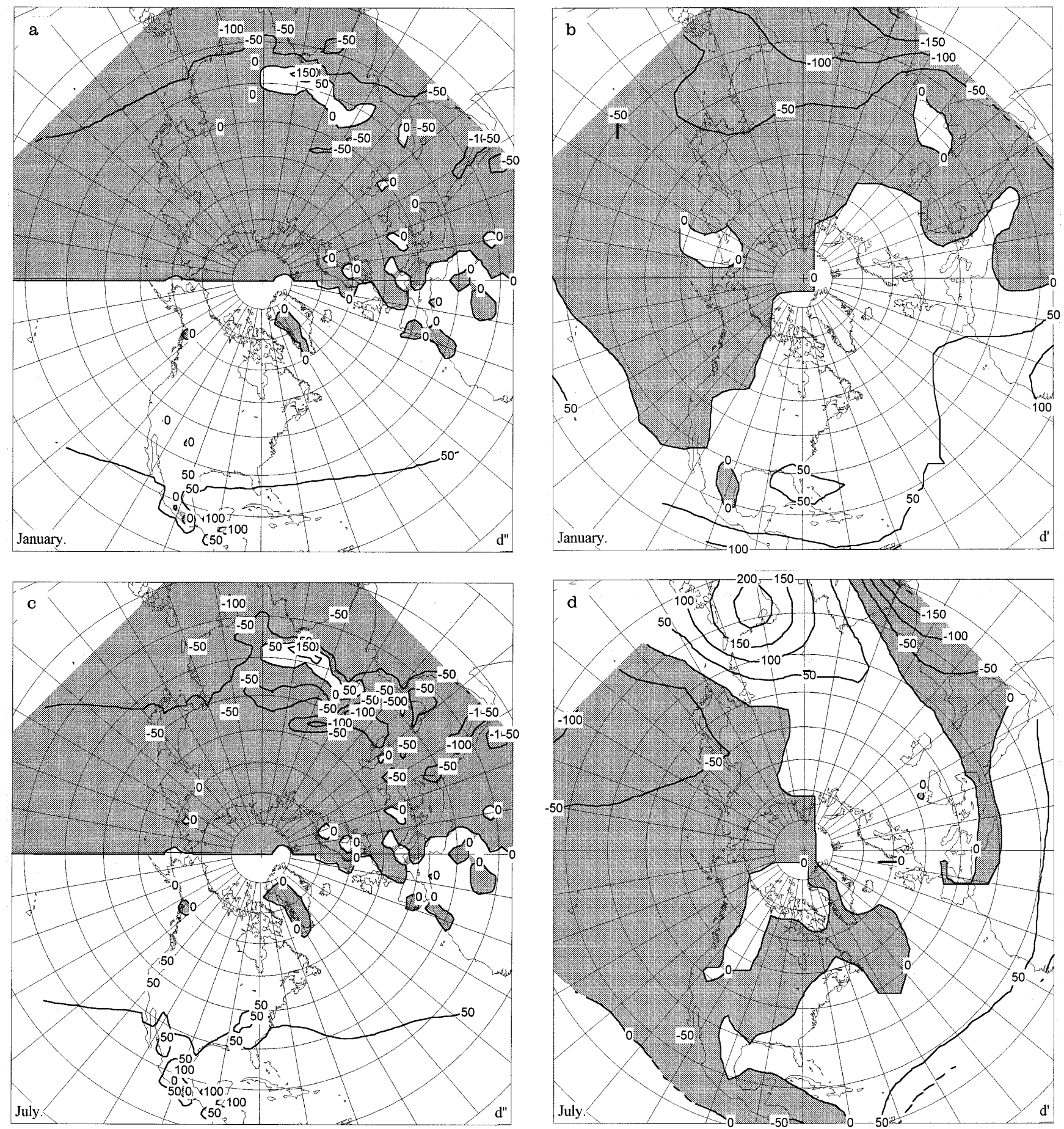

Fig. 4a-d. Geographical patterns of the $d^{\prime \prime}$ coefficient in the theoretical Eq. (46), and the $d^{\prime}$ coefficient in the Clapp et al. (1965) formula, computed in $2 \mathrm{Wm}^{-2} \mathrm{~K}^{-1}$. a Is the $d^{\prime \prime}$ coefficient for winter, $\mathbf{b}$ the $d^{\prime}$ coefficient for winter, $\mathbf{c}$ the $d^{\prime \prime}$ coefficient for summer, and $\mathbf{d}$ the $d^{\prime}$ coefficient for summer 
not zero. The statistical fields of Clapp et al.'s (1965) $c^{\prime}$ and $d^{\prime}$, (Figs. 3b, 4b) show the same characteristic zero isoline along $80^{\circ} \mathrm{W}$ and $10^{\circ} \mathrm{E}$, respectively, and suggest that the effect of the Coriolis parameter variation is present in these maps. The $r$ coefficient between the $c^{\prime \prime}$ and $c^{\prime}$ fields is 0.64 and between the $d^{\prime \prime}$ and $d^{\prime}$ fields is 0.72 , for winter in both cases.

The summer $c^{\prime \prime}$ and $d^{\prime \prime}$ maps (Figs. 3c, 4c) are quite different to the corresponding summer $c^{\prime}$ and $d^{\prime}$ maps
(Figs. 3d, 4d). The $r$ coefficients between the fields are 0.19 and -0.07 respectively. This difference may be related to atmospheric phenomena which were not included in our parametrization.

The corresponding coefficients to $a^{\prime \prime}$ and $e^{\prime \prime}$ do not exist in Eq. (2), and therefore we cannot compare these coefficients. In the maps of winter and summer, (See Fig. 5) they are negative in the whole Northern Hemisphere and it is interesting to point out that above
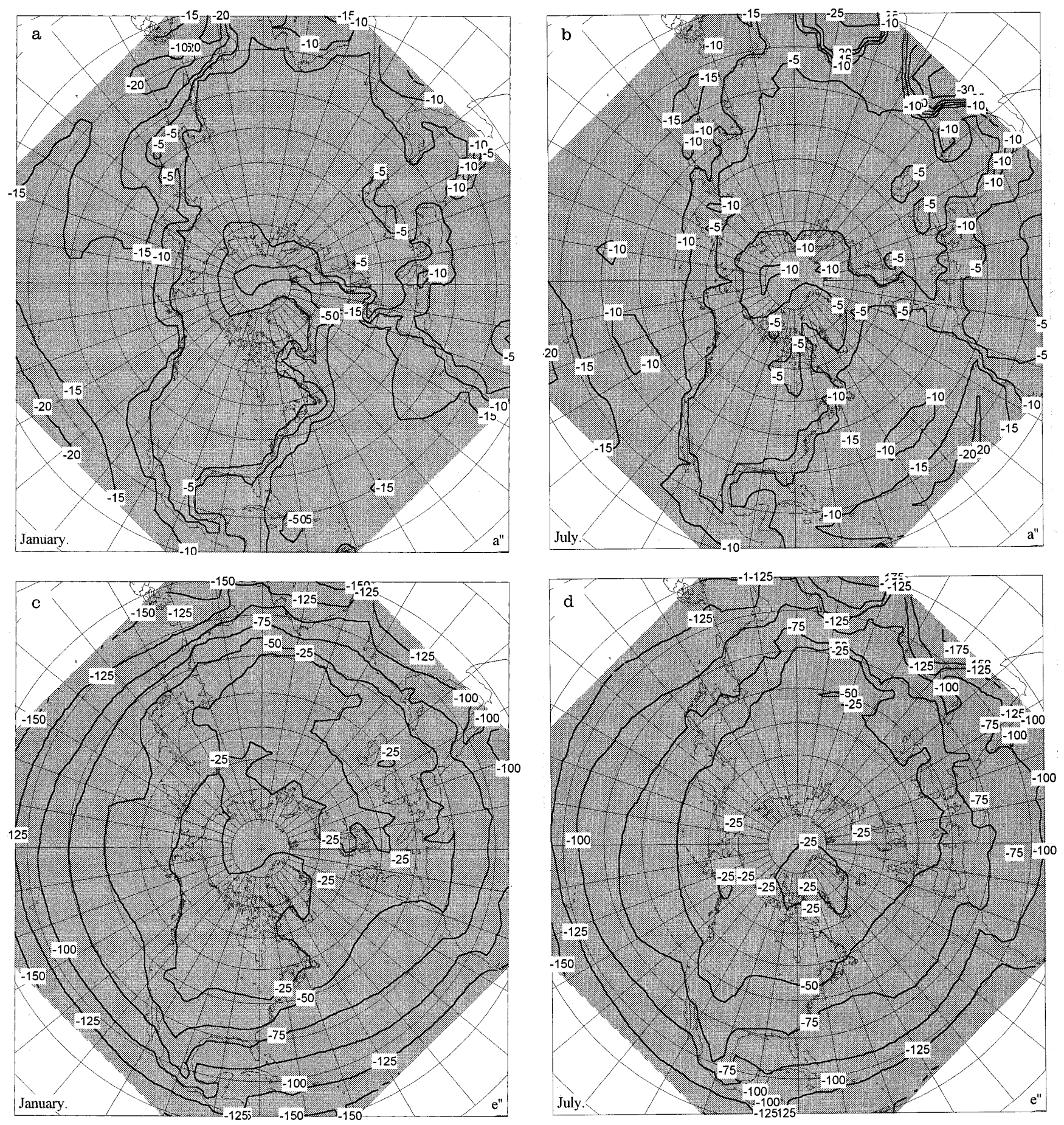

Fig. 5a-d. Geographical patterns of the $a^{\prime \prime}$ and $e^{\prime \prime}$ coefficients in the theoretical Eq. (46), computed in $2 \mathrm{Wm}^{-2} \mathrm{~K}^{-1}$. a Is the $a^{\prime \prime}$ coefficient for winter, $\mathbf{b}$ the $a^{\prime \prime}$ coefficient for summer, $\mathbf{c}$ the $e^{\prime \prime}$ coefficient for winter, and $\mathbf{d}$ the $e^{\prime \prime}$ coefficient for summer 
normal precipitation occurs with negative values of $T_{s D N}^{\prime}=T_{s}^{\prime}-T_{s N}^{\prime}$ for the case of $a^{\prime \prime}$, and with also negative values of $T_{s}^{\prime}-T_{s}^{\prime} N=\nabla^{2} T_{D N}^{\prime}$ for that of $e^{\prime \prime}$.

\section{Verification experiments for the precipitation in Mexico}

In order to compare the observed rainfall anomalies with the anomalies of the heat released by the condensation of water vapor in the clouds $\left(G_{5}-G_{5 N}\right)$, computed using our theoretical Eq. (46) and using Clapp et al.'s (1965) formula, we carried out five numerical experiments evaluating the contribution of the different terms in our formula.

In these experiments we used $700 \mathrm{mb}$ temperatures over a period of 36 months, from January 1981 to December 1983 and their corresponding normal values, both obtained from NCAR NMC Grid Point Data Set (CD-ROM) taking $T^{\prime}-T_{N}^{\prime} \approx T_{7}-T_{7 N}$. The observed data for surface air temperature anomalies which are assumed to be equal to $\left(T_{s}^{\prime}-T_{s N}^{\prime}\right)$, were obtained from the Servicio Meteorológico Nacional, Mexico. Furthermore, we used observed precipitation and its average values also from the Servicio Meteorológico Nacional for the 36 months, at 97 stations scattered in Mexico and interpolated to 23 grid points of the NMC grid used in the ATM. The interpolation was made drawing by the monthly isohyets and their corresponding normal values for each month on the map of Mexico. The isohyets were drawn taking the orography into account, in other words, according to the orographic contour. The isolines were drawn through places of approximately same height, and then were determined by the precipitation values in the 23 grid points over Mexico.

With $F_{c}$, we denote the computations using Clapp et al.'s (1965) formula, given by Eq. (2), which can be expressed as

$$
\begin{aligned}
\left(G_{5}-G_{5 N}\right)_{i, j}= & b^{\prime}\left(T^{\prime}-T_{N}^{\prime}\right)_{i, j}+c^{\prime}\left(\frac{\partial\left(T^{\prime}-T_{N}^{\prime}\right)}{\partial Y}\right)_{i, j} \\
& +d^{\prime}\left(\frac{\partial\left(T^{\prime}-T_{N}^{\prime}\right)}{\partial X}\right)_{i, j}
\end{aligned}
$$

where the derivatives respect to $Y$ and $X$ coordinates are given by Eq. (47).

$F_{2}$ denotes the experiment using our complete Eq. (46).

$F_{3}$ refers to the experiment using in Eq. (46) the three terms similar to those of Clapp et al.'s (1965) formula, i.e., omitting the $a^{\prime \prime}$ and $e^{\prime \prime}$ terms; $F_{4}$ denotes the experiment using Eq. (46), but omitting only the $e^{\prime \prime}$ term, and finally $F_{5}$ is an experiment where we have omitted only the $a^{\prime \prime}$ term in Eq. (46).

Figure 6 shows an example to illustrate the difference between the similar equations of cases $F_{c}$ and $F_{3}$ over Mexico. Figure 6a shows the percentage of normal precipitation observed in August of 1983 and Fig. 6b,c shows the corresponding computed values using cases $F_{c}$ and $F_{3}$ respectively.
The areas where the percentage of normal precipitation were above normal $(100 \%)$ are shaded, and where they were below normal are in white. Comparison of the figures, shows that there is similarity in the percentage of normal precipitation between the observed precipitation (Fig. 6a) and the $G_{5}$ anomalies computed in the $F_{3}$ case (Fig. 6c), especially in the Yucatán peninsula and Northern México where it rains practically only in summer; in contrast, the map of $G_{5}$ anomalies computed in the $F_{c}$ case has no similarity for this month, (Fig. 6b).

Table 2 shows the results of the experiments for the anomalies of $G_{5}$. In the second column are the percentages of sign correctly predicted for the 36 month period, evaluated by seasonal and annual averages for $F_{c}$ (using Clapp et al.'s (1965) formula). In the next columns are shown the excesses of percentages over $F_{c}$ when $F_{2}, F_{3}, F_{4}$ and $F_{5}$ are used.

The experiments with the complete formula $\left(F_{2}\right)$, show an excess of percentage of sign correctly simulated with respect to those using Clapp et al.'s (1965) formula $\left(F_{c}\right)$ for the annual average and for all seasons, except in summer.

To determine the contribution of the different terms in Eq. (46), we have carried out experiments $F_{3}, F_{4}$ and $F_{5}$.

In the $F_{3}$ case, when the $a^{\prime \prime}$ and $e^{\prime \prime}$ terms are neglected and Eq. (46) is similar to that of Clapp et al.'s (1965) Eq. (48), the greater percentage is positive in winter, spring and autumn but negative in summer. Comparison of the $F_{3}$ case with the complete case $\left(F_{2}\right)$ shows that the $F_{3}$ case gives a better estimation of the rainfall in spring, summer, autumn and in the annual average than the complete formula.

In the $F_{4}$ case the greater percentage is positive for all seasons, and the annual average is the same than for the $F_{3}$ case and is $4.5 \%$. Furthermore, the comparison of $\left(F_{4}-F_{c}\right)$ with $\left(F_{3}-F_{c}\right)$, shows that the inclusion of the $a^{\prime \prime}$ term improves substantially the results in summer which is the rainy season in Mexico. The contribution of the term $e^{\prime \prime} \nabla^{2}\left(T^{\prime}-T_{N}^{\prime}\right)$ is seen comparing $\left(F_{5}-F_{c}\right)$ with $\left(F_{3}-F_{c}\right)$. The results show that this term does not improve the estimation of the monthly rainfall anomalies except in autumn, when the percentage of the $F_{5}$ case is larger than that of $F_{3}$ case.

Table 2. Percentages in seasonal and annual averages of correctly computed signs of the anomalies of precipitation computed in the $F_{c}$ experiment, and compared to the results computed in the $F_{2}, F_{3}$, $F_{4}$ and $F_{5}$ experiments

\begin{tabular}{lccccc}
\hline Season & $F_{c}$ & $F_{2}-F_{c}$ & $F_{3}-F_{c}$ & $F_{4}-F_{c}$ & $F_{5}-F_{c}$ \\
\hline Winter & 56.0 & 2.5 & 2.5 & 2.9 & 0.5 \\
Spring & 52.2 & 0.9 & 3.4 & 1.4 & 1.9 \\
Summer & 52.6 & -5.3 & -2.8 & 2.5 & -5.3 \\
Autumn & 40.1 & 13.5 & 15.0 & 11.1 & 16.4 \\
Annual & 50.2 & 2.9 & 4.5 & 4.5 & 3.4 \\
\hline
\end{tabular}



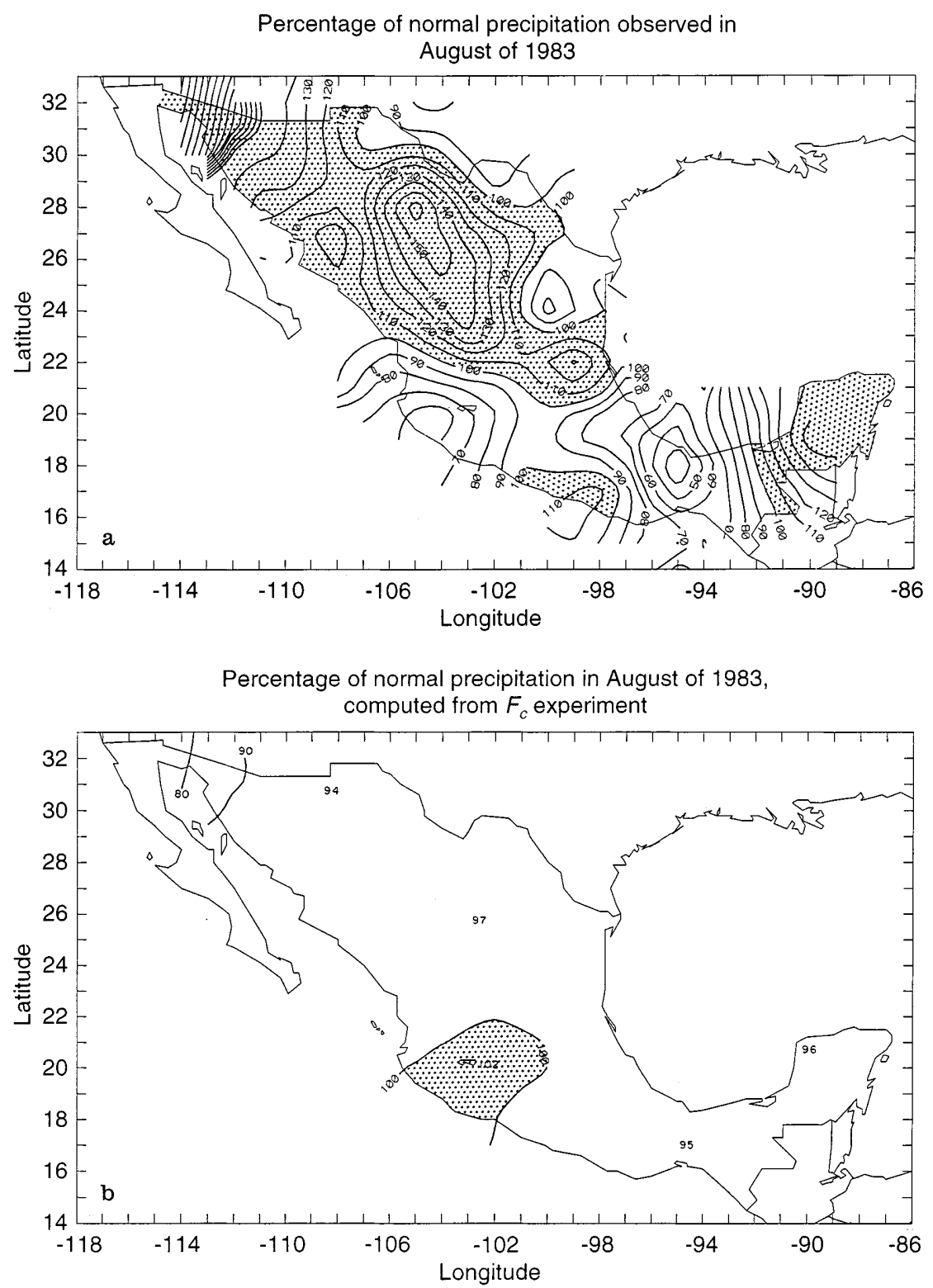

Percentage of normal precipitation in August of 1983, computed from $F_{3}$ experiment

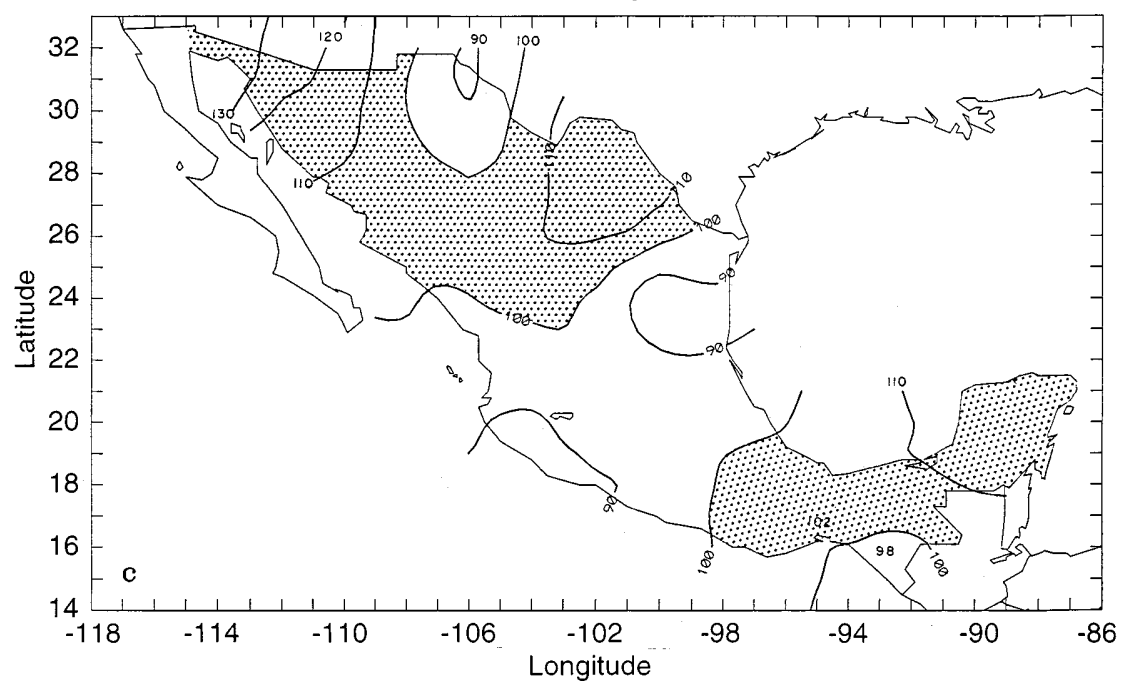

Fig. 6a-c. Percentage of normal precipitation in August 1983 in Mexico. The areas where the percentage is above $100 \%$ are shaded. a Observed precipitation, b computed precipitation in $F_{c}$ experiment, and c computed precipitation in $F_{3}$ experiment 


\section{Concluding remarks}

1. In the annual average all our formulas show better results than that Clapp et al.'s (1965) one in the precipitation anomalies simulation.

2. It is important to notice that the $F_{4}$ experiment, in which the surface temperature anomaly is included, besides the type of terms that appears in the Clapp et al.'s (1965) formula and for the $F_{3}$ formula (mid tropospheric temperature anomaly and its $X$ and $Y$ derivatives), there is a significant improvement in the estimation of rainfall in summer, the rainy season in Mexico. Therefore, this experiment suggests that the surface temperature anomaly may produce a better parametrization for this season.

3. A more sophisticated parametrization of precipitation than the one used in this work would not necessarily give an improvement in the estimation of the anomalies of precipitation in the Northern Hemisphere and in particular in Mexico. However, the contribution to the $G_{5}$ anomalies given by the $c^{\prime \prime}$ and $d^{\prime \prime}$ terms in Eq. (46) could possibly be substantially improved, with a finer resolution in the computation of the orographic slope, $h_{x}$ and $h_{y}$ especially in Mexico's case. We think that it is possible to use a finer resolution nested grid, superposed on the NMC grid in mountain regions.

4. The assumption of geostrophic wind in Eq. (22), in order to evaluate the rotational of wind stress, could be the reason that the $e^{\prime \prime} \nabla^{2}\left(T^{\prime}-T_{N}^{\prime}\right)$ term in Eq. (46) does not improve the estimation of $G_{5}$ anomalies. A more sophisticated parametrization of surface wind could be obtained, by introducing an angle between the wind and the isobars (Holton, 1972).

5. Another source of error could be to assume $\delta=\delta^{\prime}=1$ in the integrals (41) which may overvalue the precipitation at subsidence zones as in the arid zones of northern Mexico.

We think that these measures in (3), (4) and (5), would improve the calculation of the coefficients $c^{\prime \prime}, d^{\prime \prime}$ and $e^{\prime \prime}$ and maybe the correlation coefficient between our $c^{\prime \prime} d^{\prime \prime}$ and their corresponding $c^{\prime}, d^{\prime}$, Clapp et al.'s (1965) coefficients will be increased in summer, and it would improve the results of the summer season in Table 2.

6. At present, there are improved precipitation and temperature data so that other alternatives are:

To use the statistical Clapp et al. (1965) formula in the form of

$R_{D N}=b T_{7 D N}+c U_{7 D N}+d V_{7 D N}$

without using the thermal wind hypothesis. In this case it is necessary to have a model to predict explicitly $U_{7 D N}$ and $V_{7 D N}$. In the case of a model which predicts only $T_{7 D N}$ (as ATM does), another option is to search for a statistical formula in the form of

$G_{5 D N}=b^{\prime} T_{7 D N}+c^{\prime} \frac{\partial T_{7 D N}}{\partial x}+d^{\prime} \frac{\partial T_{7 D N}}{\partial y}$

with linear regression coefficients $b^{\prime}, c^{\prime}$ and $d^{\prime}$ recast.
Another alternative is to use Adem's water vapor conservation parametric method described in a previous paper (Adem, 1968a).

Finally, in future work we will verify our formula in other continental and oceanic areas, as well as in the total region of integration of the NMC grid, using the best available data.

Acknowledgements. The authors would like to thank E. E. Villanueva for fruitful discussions and Alejandro Aguilar Sierra for computational support. The Editor in Chief thanks A. Berger and another referee for their help in evaluating this paper.

\section{References}

Adem, J., On the physical basis for the numerical prediction of monthly and seasonal temperatures in the troposphere-oceancontinent system, Mon. Weather Rev., 92, 91-103, 1964.

Adem, J., Experiments aiming at monthly and seasonal numerical weather prediction, Mon. Weather Rev., 93, 495-503, 1965.

Adem, J., Parametrization of atmospheric humidity using cloudiness and temperature, Mon. Weather Rev., 95, 83-88, 1967a.

Adem, J., Relations among wind, temperature, pressure, and density, with particular reference to monthly averages, Mon. Weather Rev., 95, 531-539, 1967b.

Adem, J., A parametric method for computing the mean water budget of the atmosphere, Tellus, 20, 621-632, 1968a.

Adem, J., Long range numerical prediction with a time average thermodynamical model. Part 1) the basic equations, Internal report of Extended Forecast Division, NMC, Weather Bureau, ESSA, Washington D.C. (Available on request to Centro de Ciencias de la Atmósfera, UNAM, 04510 México D.F., México), 1968b.

Adem, J., On the seasonal effect of orbital variations on the climates of the next 4000 years. Annales Geophysicae, 14, 11981206, 1996.

Adem, J., and Donn, W. L., Progress in monthly climate forecasting with a physical model. Bull. Am. Meteorol. Soc., 62, 1666-1675, 1981.

Adem, J., Ruiz, A., Mendoza, V. M., Garduño, R., and Barradas, V., Recent experiments on monthly weather prediction with the Adem thermodynamic climate model, with special emphasis on Mexico, Atmósfera, 8, 23-34, 1995.

Clapp, P. F., Scolnik, S. H., Taubensee, R. E., and Winninghoff, F. J., Parametrization of certain atmospheric heat sources and sinks for use in a numerical model for monthly and seasonal forecasting, Internal Report, Extended Forecast Division, (Available on request to Climate Analysis Center NWS/NOAA, Washinton D.C., 20233), 1965.

Holton, J. R., An introduction to dynamic meteorology, Academic Press, New York N.Y., pp. 319, 1972.

Kasahara, A., and Washington, W. M., NCAR global general circulation model of the atmosphere, Mon. Weather Rev., 95, 389-402, 1967.

Kuo, H. L., On formation and intensification of tropical cyclones through latent heat release by cumulus convection, J. Atmos. Sci., 22, 40-63, 1965.

Krishnamurti, T. N., An experiment in numerical prediction in the equatorial latitudes, Q. J. R. Meteorol. Soc., 95, 594-620, 1969.

Mendoza, V. M., Un Modelo Termodinámico del Clima, Facultad de Ciencias, UNAM, México D.F., México, pp. 184, (Ph D Thesis), 1992.

Negri, A. J., Adler, R. F., Maddox, R. A., Howard, K. W., and Keehn, P. R., A regional rainfall climatology over Mexico and the southwest United States derived from passive microwave and geosynchronous infrared data, J. Clim., 6, 2144-2161, 1993.

Washington, W. M., and Williamson, D. L., A description of the NCAR global circulation models, in Methods in computational physics, 17, Academic Press, N.Y., pp. 337, 1977. 